\title{
Case report- a case of Creutzfeldt-Jakob disease
}

\author{
Sontakke A. ${ }^{1}$, Khare B. ${ }^{2 *}$, Srivastava B. ${ }^{3}$, Waran M. ${ }^{4}$, Tyagi B. ${ }^{5}$ \\ DOI: https://doi.org/10.17511/ijmrr.2019.i04.01
}

\footnotetext{
${ }^{1}$ Ajay Sontakke, Resident, Department of Medicine, DVVPF's Medical College, Ahmednagar, Maharashtra, India.

${ }^{2 *}$ Brig A. B. Khare (Retd), Associate Professor, Department of Medicine, DVVPF's Medical College, Ahmednagar, Maharashtra, India.

3 Brig A.K. Srivastava (Retd), Associate Professor, Department of Medicine, DVVPF's Medical College, Ahmednagar, Maharashtra, India.

${ }^{4}$ Marcia Waran, Professor, Department of Medicine, DVVPF's Medical College, Ahmednagar, Maharashtra, India.

$\mathbf{5}$ Brig Arun Tyagi (Retd), Professor \& HOD, Department of Medicine, DVVPF's Medical College, Ahmednagar, Maharashtra, India.
}

Creutzfeldt-Jakob Disease (CJD) is a rare invariably fatal neurodegenerative disease believed to be caused by an abnormal isoform of cellular infectious glycoprotein called prion protein. Though it is arare disease; yet it is the most common among prion diseases. Clinical presentation consists of rapidly progressive loss of memory, cognitive \& visual disturbance, lack of coordination, myoclonus, cerebellar, pyramidal and extra pyramidal signs, akineticmutism \& with progression of disease deterioration in higher mental functions become more pronounced. Periodic sharp triphasic wave complexes on EEG, high signal abnormalities in caudate nucleus and putamen on diffusion weighted (DW) or FLAIR MRI of Brain and positive 14-3-3 protein in CSF substantiate the diagnosis of CJD but definitive diagnosis is established by brain biopsy or autopsy materials. We report a case of 58-year old female patient who was admitted with complaints of rapidly progressive dementia, cognitive disturbance, blurring of vision and myoclonic jerks. Initial MRI brain and CSF findings were normal. Differential diagnoses that can present with rapidly progressive dementia and thereby mimic sporadic Creutzfeldt-Jakob disease were considered after review of literature. In EEG triphasic wave complexes were seen, repeat DWMRI after two weeks showed bilateral hyper-intensities in basal ganglia involving caudate nucleus and putamen, suggesting a diagnosis of probable CJD on the basis of center for disease control and prevention (CDC) criteria. The case is reported because of its rarity and also to emphasise that patients with rapidly progressive dementia, associated visual and cognitive disturbances and myoclonus should be investigated with DW MRI, EEG\&CSF for diagnosis of CJD.

Keywords: Creutzfeldt-Jakob Disease (CJD), Progressive Dementia, Neurodegenerative, Prion Protein

\section{Corresponding Author}

Brig A. B. (Retd) Khare, Associate Professor, Department of Medicine, DVVPF's Medical College, Ahmednagar, Maharashtra, India.

Email: dr.ab.khare@gmail.com

\section{How to Cite this Article}

Sontakke A, Khare AB, Srivastava AK, Waran M, Tyagi A. Case report- a case of Creutzfeldt-Jakob disease. Int J Med Res Rev. 2019;7(4):253-258. Available From https://ijmrr.medresearch.in/index.php/ijmrr/article/ view/1078

\section{To Browse}

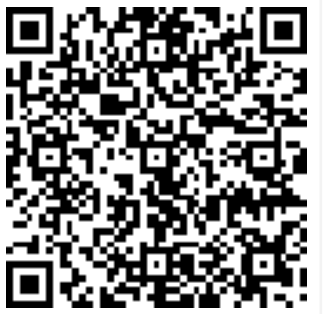

Manuscript Received 2019-06-26

Conflict of Interest No
Review Round 1 2019-07-01

Funding

Nil

Review Round 2
2019-07-10
Ethical Approval
Yes

Review Round 2

Yes
Review Round 3

Accepted

2019-07-15

Plagiarism X-checker

$5 \%$

(c) 2019 by Ajay Sontakke, A. B. Khare, A.K. Srivastava, Marcia Waran, Arun Tyagi and Published by Siddharth Health Research and Social Welfare Society. This is an Open Access article licensed under a Creative Commons Attribution 4.0 International icense https://creativecommons.org/licenses/by/4.0/ unported [CC BY 4.0 ] 


\section{Introduction}

Creutzfeldt-Jakob disease (CJD) is a progressive, transmissible and fatal human prion disease characterized by rapidly progressing dementia accompanied by visual and cerebellar abnormalities, pyramidal and extra pyramidal dysfunction, myoclonus and akinetic mutism. It is divided into four categories: sporadic (SCJD), familial (fCJD), iatrogenic (iCJD), and variant forms (VCJD). SCJD accounts for $85-95 \%$ of total CJD cases, and fCJD for $10 \%$ of cases. iCJD and VCJD comprise about of 2-5\% CJD cases [1].

Mean age at the onset is 60 years with a yearly incidence of approximately one per million. SCJD is suspected when patients have significant rapid progressive dementia, visual dysfunction, cerebellar /function abnormalities, and pyramidal/extra pyramidal signs.

However, aberrant behaviour, such as anxiety, irritability, social withdrawal, changes in memory, judgment difficulties, and other psychiatric symptoms, are frequently reported as early signs but can be easily ignored [2]. MRI brain can be normal in the earlier stage of the disease; however, the signal alterations precede the changes in EEG and CSF abnormalities. Combined diffusion weighted (DW) and FLAIR images in MRI brain have high sensitivity (91\%) and specificity (95\%) for CJD [3].

We report a case of SCJD who presented with cognitive impairment, behavioural changes, and visual disturbances. The patient's dementia progressed rapidly and followed with myoclonic jerks at a later stage. It is often difficult and challenging task to diagnose CJD pre-mortem
Because of a lack of awareness and/or low index of suspicion of this rare disease and requirement of brain biopsy for definitive diagnosis and therefore, most of the cases remain undiagnosed or are diagnosed post-mortem.

\section{Case Report}

This 58-year old house wife, matriculate, righthanded, was brought to the hospital with history of gradual onset memory loss, cognitive disturbance and visual disturbance in form of blurring of vision of both eyes. The memory loss was short term, gradual and progressive and it was associated with emotional liability and behavioural changes like depression and aggression.

Patient gradually developed cognitive dysfunction like persistent repetition of words and inability to read and recognise familiar objects, inability to perform skilful learned activities (inability to read or to ignite the LPG stove, inability to dress/undress herself). Patient also developed reduced vision in both eyes in that the objects were not sharp or focused. The visual disturbance was gradual in onset and progressive and was not associated with pain, redness or discharge from eyes or headache.

The visual disturbance progressed to such extent that she was unable to perform routine activities. The patient denied any history of fever, vomiting, trauma, seizure, any drug intake or intake of raw livestock or brain matter. There was no history suggestive of hallucinations, illusion, delusions and weakness in any part of the body or difficulty in swallowing. Past history and family history were not contributory.

Table 1- CDC'S diagnostic criteria for Creutzfeldt-Jakob disease (CJD), 2018 [17].

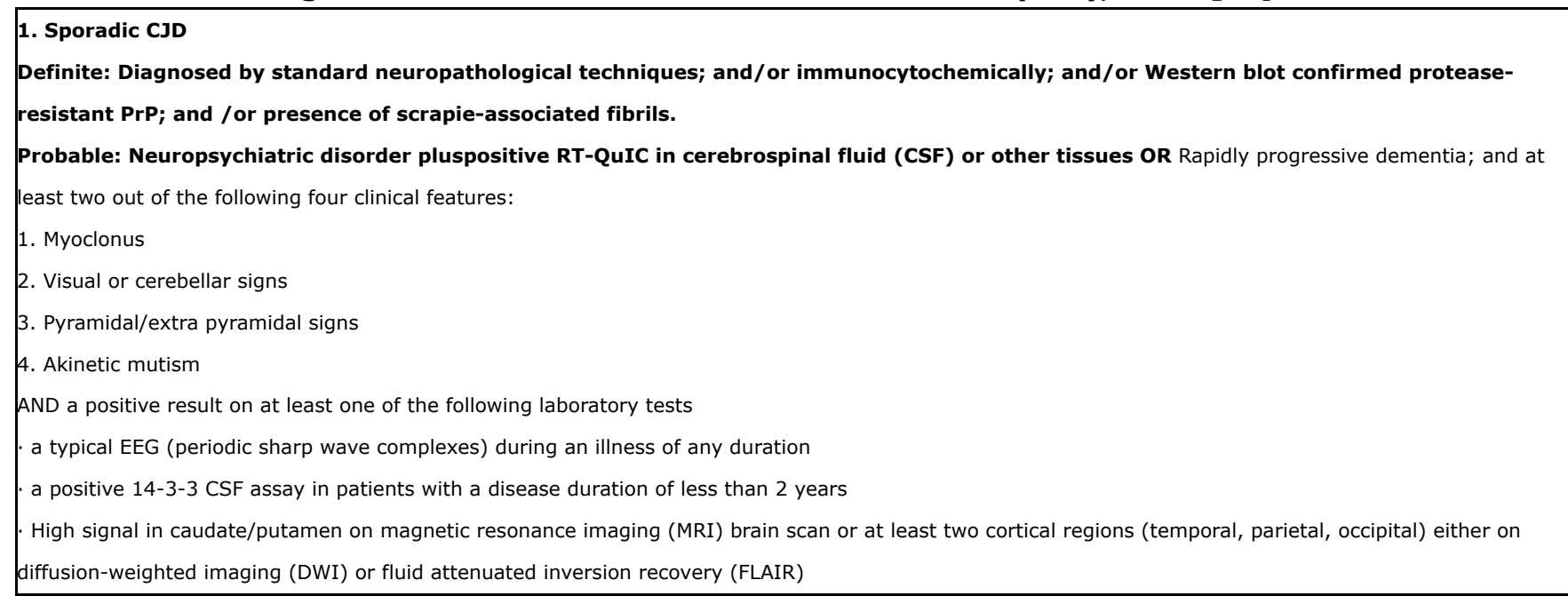




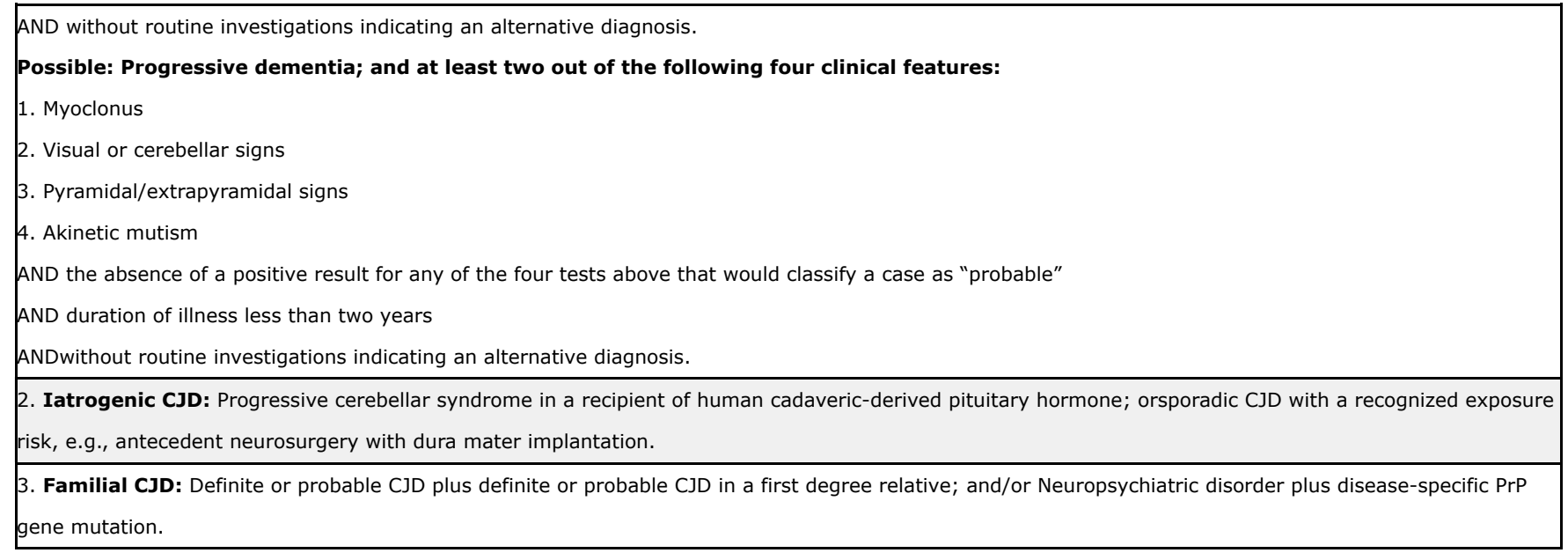

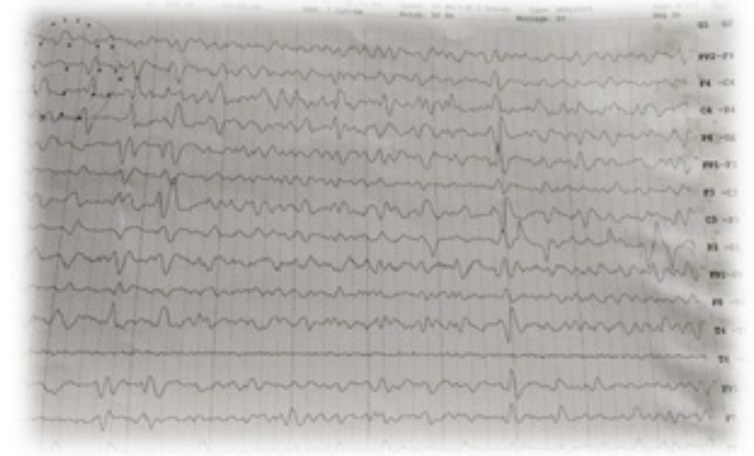

Figure 1: EEG- Diffuse background slowing with periodic repetitive triphasic wave complexes

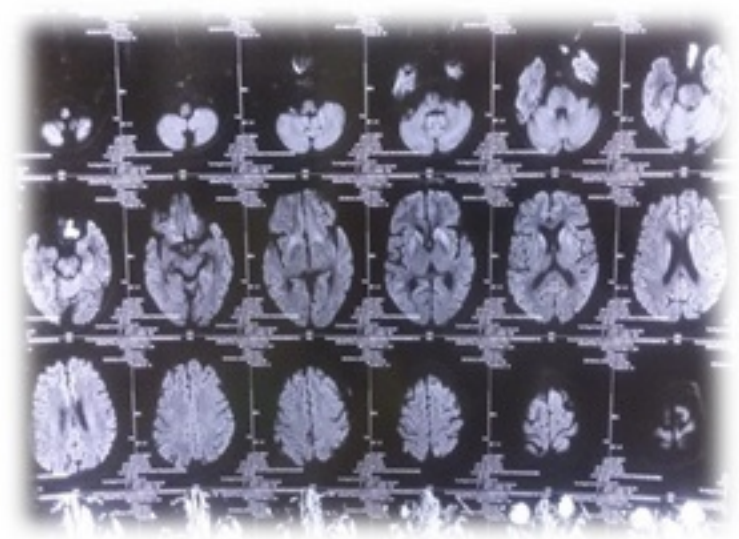

\section{Figure 2. Brain- Diffusion Weighted (DW) images}

Clinical examination revealed an averagely built, well nourished, irritable lady. Her vital parameters were within normal range and general examination was unremarkable. On CNS examination, she was conscious, uncooperative, disoriented to time, place and person.
Her pupils were normal in size and bilaterally reacting to light, fundus examination was normal. Muscle nutrition, tone, power and reflexes were normal but she had continuous myoclonus in extensors of both upper limbs and she was unable to walk. There were no meningeal signs. Though detailed cranial nerve, sensory or cerebellar examination was not possible because of patient being uncooperative, there was no overt cranial nerve, sensory or cerebellar deficit. MRI brain plain was done and no significant abnormality detected.

A differential diagnosis of SCJD, meningoencephalitis, cerebral autosomal dominant arteriopathy with subcortical infarcts and leuko encephalopathy (CADASIL), Alzheimer's disease \& paraneoplastic encephalomyelitis was considered on the basis of history and clinical examination. Routine blood counts, biochemistry and CSF examination were within normal limit. MRI brain plain was done and no significant abnormality detected. EEG was done and showed diffuse background slowing with superadded repetitive triphasic complexes supporting diagnosis of CJD. The patient was started on steroids (Prednisolone $1 \mathrm{mg} / \mathrm{kg}$ ), haloperidol, physiotherapy and supportive therapy. Serum Autoimmune antibody panel, NMDA receptor antibody, Positron Emission Tomography scan (PETCT) were negative, thus effectively ruling out other differentials. The patient's condition continued to deteriorate despite the treatment, in form of rapid progression of dementia and cognitive dysfunction, difficulty in swallowing, inability to walk and spasticity of all limbs.

Repeat MRI brain after two weeks showed bilateral hyper intensities in basal ganglia involving caudate nucleus and putamen with mild prominence along bilateral cerebral convexity in diffusion weighted (DW) images. 
This case was diagnosed with probable CJD on the basis of 2010 CDC criteria for SCJD (table 1) in view of history of rapidly progressive dementia with cognitive dysfunction and visual disturbances with myoclonus and positive EEG and MRI brain finding. Patient was discharged on request and advised general nursing care and supportive therapy at home.

\section{Discussion}

Prusiner hypothetically proposed prions as causative infectious agent of CJD in 1982. In humans, prion protein gene is localized on the short arm of the chromosome 20. Methionine/valine polymorphism on codon 129 of this gene is found to be associated with CJD. Infective prion (PrPSc) is a posttranslational product resulting from defective folding of the normal prion. These abnormal prions accumulate in cells leading to the formation of vacuolar degeneration and some fibrillar structures; subsequently brain takes the form of a sponge resulting in death [4].

Diagnosing CJD in the early stages is challenging due to the extremely low incidence and highly varied initial presentation. Other rapidly progressive dementias can also resemble SCJD because of the overlap of motor, behavioural, psychiatric, and cognitive manifestations, which make the diagnosis of SCJD in the early stages even more difficult. However, it is important to consider and diagnose it in early stages because of its poor prognosis. Twenty percent of patients may first manifest with behavioural symptoms, such as agitation, irritability, and depression in the early stages [1].

In a study of 248 SCJD cases in Germany, $64 \%$ of patients had agitation, $45 \%$ had hallucinations, $50 \%$ had anxieties, and $37 \%$ had depression at the onset of the disease [5]. The myoclonus may be absent at the first presentation but usually appears in the advanced stages of SCJD[6]. Akinetic mutism is usually manifested at the end stage of SCJD [7]. A probable SCJD case was presented with typical symptoms and clinical course with rapidly progressive dementia, myoclonus, ataxia and behavioural symptoms. SCJD should always be included in the differential diagnosis when the diagnosis of dementia is associated with behavioural disturbance, neurological findings, or psychiatric symptoms. The onset at relatively early age and female preponderance of the disease has been documented in a number of studies $[8,9,10]$.
Our patient did not haveany family history and therefore she was diagnosed as SCJD. FCJD is an even rarer entity; only one or two cases have been reported by González Duarte et al[10], Mehndiratta et al [8] and Chandra et al [11]. The classical EEG changes $n$ SCJD are generalized periodic sharp waves, biphasic and triphasic waves at a rate of one per second, as seen in our patient. EEG has a sensitivity of $67 \%$ and specificity of $74-86 \%$ in the diagnosis of CJD [10].

Repeated EEG during the course of disease increases the probability of demonstrating characteristic EEG abnormality. However, similar EEG findings are sometimes possible in Hashimoto's encephalopathy. Imaging study of our patient revealed bilateral basal ganglia hyper intensities. González Duarte et al and Mahale et al. also reported six of their eight patients showing symmetrical basal ganglia hyper intensities, which showed restriction under DWI imaging, however cortical signal changes (parieto-occipital, frontal and temporal) did not show restriction $[10,12]$.

Recently, Biswas et al [13] had shown 100\% (ten) of their patients showing abnormalities on imaging (Basal ganglionic signal changes- 8 patients and parieto- occipital signal changes- 2 patients). Magnetic resonance imaging of brain can be normal in the earliest stages of CJD and it may show only atrophy in the terminal stage of the illness; classical signal alterations might have disappeared [14]. The detection of the 14-3-3 protein in CSF is one of the markers for diagnosis of CJD and has sensitivity of $92 \%$ and specificity of $80 \%[15,16]$. According to Zerr et al. the imaging findings arecomparable to elevated levels of the 14-3-3 protein in the diagnosis of probable SCJD [17]. Unfortunately, we were not able to assay CSF 14-3-3 protein in our case because of financial constraints.

The new diagnostic modality 'Real-time quakinginduced conversion' (RT-QuIC) assays have made a considerable impact on its clinical diagnosis. This technique exploits the ability of the misfolded pathological form of prion protein (PrPSC) found in cerebrospinal fluid (CSF) to induce conversion of normal PrP to the misfolded form, which subsequently aggregates. The formation of these aggregates of misfolded PrP is monitored in real time using fluorescent dyes. The current sensitivity ofCSFRT-QuIC undertaken at the UK National CJD Research \& SurveillanceUnit is $92 \%$ and the specificity is $100 \%$ [18] 
The time interval between the onset of the symptoms to the diagnosis was two months in our case. Usually, the time interval for diagnosis ranges from 1-12 months. The mean survival of CJD patients is 5 months and about $80 \%$ of patients succumb to disease within one year from onset [19]. The mean duration from onset of symptoms to the time of death is 6.6 months (Range: 3-14 months).

\section{Conclusion}

Patients presenting with rapidly progressive dementia, associated behavioural and visual abnormalities\& myoclonus should be suspected for SCJD and investigated with DW MRI, EEG \& CSF for 14-3-3 protein and Real-time quaking-induced conversion' (RT-QuIC) assays for early diagnosis of this rare and fatal disease. Early diagnosis can help provide quality end of life care and support to patient and family.

Take Home Message: The patient presenting with rapidly progressive dementia behavioural changes, myoclonus \& visual disturbances may not have any initial MRI brain changes.

Repeat DW MRI brain can detect characteristic findings suggestive of SCJD like bilateral hyperintensities in basal ganglia involving caudate nucleus and putamen with mild prominence along bilateral cerebral convexity after 2 to 3 weeks interval.

\section{Reference}

01. Chen C, Dong XP. Epidemiological characteristics of human prion diseases. Infect Dis Poverty. 2016;5(1)47.

DOI: $\quad 10.1186 / s 40249-016-0143-8 \quad$ [Crossref]

02. Rabinovici GD, Wang PN, Levin J, Cook L, Pravdin M, Davis J. First symptom in sporadic Creutzfeldt-Jakob disease. Neurol. 2006;66(2)286-7.

DOI: $\quad 10.1212 / 01 . w n l .0000196440 .00297 .67$

[Crossref]

03. Young GS, Gesch wind MD, Fischbein NJ, Martindale JL, Henry RG, Liu S, et al. Diffusionweighted and fluid-attenuated inversion recovery imaging in Creutzfeldt-Jakob diseasehigh sensitivity and specificity for diagnosis. AJNR Am J Neuroradiol. 2005;26(6)1551-62.

[Crossref]
04. Hill AF, Joiner S, Wadsworth JD, Sidle KC, Bell JE, Budka $\mathrm{H}$, et al. Molecular classification of sporadic Creutzfeldt-Jakob disease. Brain. 2003;126(Pt 6)1333-46.

DOI: $10.1093 /$ brain/awg125 [Crossref]

05. Krasnianski A, Bohling GT, Harden M, Zerr I. Psychiatric symptoms in patients with sporadic Creutzfeldt- Jakob disease in Germany. J Clin Psychiatry. 2015;76(9)1209-15. DOI: $10.4088 /$ JCP.13m08915 [Crossref]

06. Collins SJ, Sanchez-JuanP, Masters CL, Klug GM, van Duijn C, Poleggi A, et al. Determinants of diagnostic investigation sensitivities across the clinical spectrum of sporadic Creutzfeldt-Jakob disease. Brain. 2006;129(Pt 9)2278-87.

DOI: $10.1093 /$ brain/awl159 [Crossref]

07. Nakatani E, Kanatani Y, Kaneda H, Nagai Y, Teramukai S, Nishimura T, et al. Specific clinical signs and symptoms are predictive of clinical course in sporadic Creutzfeldt-Jakob disease. Eur J Neurol. 2016;23(9)1455-62.

DOI: $10.1111 /$ ene.13057 [Crossref]

08. Mehndiratta MM, Bajaj BK, Gupta M, Anand R, Tatke $M$, et al. Creutzfeldt-Jakob disease- Report of 10 cases from North India. Neurol India. $2001 ; 49(4) 338-41$.

[Crossref]

09. Velásquez-Pérez L, Rembao-Bojorquez D, Guevara J, Guadarrama-Torres RM, TrejoContreras A. Creutz feldt - Jakob disease in Mexico. Neuropathol. 2007;27(5)419-28. DOI: $10.1111 /$ j.1440-1789.2007.00807.x [Crossref]

10. González-Duarte A, Medina Z, Balaguer RR, Calleja JH. Can prion disease suspicion be supported earlier?- Clinical, radiological and laboratory findings in a series of cases. Prion. 2011;5(3)201-7.

DOI: 10.4161/pri.5.3.16187 [Crossref]

11. Chandra SR, Issac TG, Philip M, Gadad V. Creutz feldt-Jakob Disease Phenotype and Course- Our Experience from a Tertiary Center. Indian J Psychol Med. 2016;38(5)438-442.

DOI: $\quad 10.4103 / 0253-7176.191376 \quad$ [Crossref] 
12. Mahale RR, Javali $M$, Mehta A, Sharma $S$, Acharya $P$, Srinivasa R. A study of clinical profile, radiological and electroencephalographic characteristics of suspected Creutzfeldt-Jakob disease in a tertiary care centre in South India. J Neurosci Rural Pract. 2015;6(1)39-50.

DOI: 10.4103/0976-3147.143189 [Crossref]

13. Biswas A, Khandelwal N, Pandit A, Roy A, Guin DS, Gangopadhyay $G$, et al. Case series of probable sporadic Creutzfeldt-Jakob disease from Eastern India. Ann Indian Acad Neurol. 2013;16(4):659-63.

DOI: 10. 4103/0972-2327.120486 [Crossref]

14. Pasha SA, Ankamma Rao, Phani Bhushan, Bhaskara Rao B, Nayak P. Case Report of Clinically Probable Sporadic Creutzfeldt - Jakob Disease from A Tertiary Care Hospital in South India. Ann Alzheimers Dement Care. 2(1)013017.

DOI: 10.17352/aadc.000003 [Crossref]

15. Zerr I, Pocchiari M, Collins S, Brandel JP, de Pedro Cuesta J, Knight RS, et al. Analysis of EEG and CSF 14-3-3 proteins as aids to the diagnosis of Creutzfeldt-Jakob disease. Neurol. 2000;55(6)811-5.

DOI: $10.1212 /$ wnl.55.6.811 [Crossref]
16. Muayqil T, Gronseth G, Camicioli R. Evidencebased guideline- diagnostic accuracy of CSF 143-3 protein in sporadic Creutzfeldt-Jakob disease- report of the guideline development subcommittee of the American Academy of Neurology. Neurol. 2012;79(14)1499-506.

DOI: $10.1212 /$ WNL.0b013e31826d5fc3 [Crossref]

17. Zerr I, Kallenberg K, Summers DM, Romero C, Taratuto A, Heinemann $U$, et al. Updated clinical diagnostic criteria for sporadic Creutzfeldt-Jakob disease. Brain. 2009;132(Pt 10)2659-68.

DOI: 10.1093/brain/awp191 [Crossref]

18. Green AJE. RT-QuIC- a new test for sporadic CJD. Pract Neurol. 2019;19(1)49-55.

DOI: 10.1136/practneurol-2018-001935 [Crossref]

19. Brown $P$, Gibbs CJ Jr, Rodgers-Johnson $P$, Asher DM, Sulima MP, Bacote A, et al. Human spongiform encephalopathy- the National Institutes of Health series of 300 cases of experimentally transmitted disease. Ann Neurol. 1994;35(5)513-29.

DOI: 10.1002/ana.4103 50504 [Crossref] 